\title{
Long non-coding RNA AWPPH interacts with ROCK2 and regulates the proliferation and apoptosis of cancer cells in pediatric T-cell acute lymphoblastic leukemia
}

\author{
XIAOHUI LI, FEIFEI SONG and HONGQIANG SUN \\ Department of Pediatrics, The First Clinical Hospital Affiliated to Harbin Medical University, \\ Harbin, Heilongjiang 150001, P.R. China
}

Received January 9, 2019; Accepted April 27, 2020

DOI: $10.3892 / \mathrm{ol} .2020 .12102$

\begin{abstract}
The long non-coding (lnc)RNA associated with poor prognosis of hepatocellular carcinoma (AWPPH) serves as an oncogene in several cancers, such as liver and bladder cancers, however, to the best of our knowledge, its function in T-cell acute lymphoblastic leukemia is unknown. The results of the present study revealed that the expression levels of lncRNA AWPPH and Rho-associated protein kinase 2 (ROCK2) were upregulated in the bone marrow of patients with pediatric T-cell acute lymphoblastic leukemia compared with healthy controls. Expression levels of lncRNA AWPPH and ROCK2 were positively correlated with each other. IncRNA AWPPH and ROCK2 overexpression promoted the proliferation and inhibited the apoptosis of Loucy cells, an acute lymphoblastic leukemia cell line. Overexpression of lncRNA AWPPH resulted in upregulation of ROCK 2 expression in Loucy cells. Similarly, ROCK2 overexpression also resulted in upregulation of lncRNA AWPPH in Loucy cells, suggesting an element of reciprocity in the function of lncRNA AWPPH and ROCK2. It was concluded that IncRNA AWPPH promoted the proliferation and inhibited the apoptosis of cancer cells in pediatric T-cell acute lymphoblastic leukemia possibly through interactions with ROCK2.
\end{abstract}

\section{Introduction}

Acute lymphoblastic leukemia (ALL) is a type of malignancy that develops in the thymus from an immature thymocyte (1). ALL is caused by the accumulation of genetic and epigenetic aberrations, which results in altered cell differentiation,

Correspondence to: Dr Xiaohui Li, Department of Pediatrics, The First Clinical Hospital Affiliated to Harbin Medical University, 2075 Qunli Seventh Avenue, Harbin, Heilongjiang 150001, P.R. China E-mail: kjoan17@163.com

Key words: T-cell acute lymphoblastic leukemia, long non-coding RNA associated with poor prognosis of hepatocellular carcinoma, Rho-associated protein kinase 2, proliferation, apoptosis proliferation, apoptosis and self-renewal capacity (1). T-cell ALL (T-ALL) accounts for $\sim 15 \%$ of all cases of ALL in children and $25 \%$ of cases in adults $(2,3)$. Studies in the past several decades have identified a considerable number of genetic factors that are involved in the development and progression of T-ALL $(4,5)$. However, the molecular signaling pathways involved in the progression of ALL are not well understood.

Long non-coding RNAs (lncRNAs) are sequences of RNA > 200 nucleotides long involved in regulating a range of physiological and pathophysiological processes (6). Altered expression of various lncRNAs has been demonstrated to promote cancer development, and some differentially expressed lncRNAs may possess clinical potential in treating patients with cancer $(7,8)$. IncRNA associated with poor prognosis of hepatocellular carcinoma (AWPPH) is a recently identified oncogenic lncRNA in liver and bladder cancer $(9,10)$. In liver cancer, lncRNA AWPPH expression is increased and promotes cancer progression by interacting with Y-box binding protein 1 (9). In bladder cancer, lncRNA AWPPH is involved in the regulation of cancer progression by regulating the activities of the SMAD family member 4 via the enhancer of zeste 2 polycomb repressive complex 2 subunit (10). IncRNA AWPPH expression was additionally upregulated in glioma based on our preliminary transcriptome analysis data (data not shown). In the present study, it was demonstrated that lncRNA AWPPH may regulate the cancerous behaviors of cells in pediatric T-ALL by interacting with the Rho-associated protein kinase 2 (ROCK2), a well-characterized oncogene which is expressed in different types of cancer (11).

\section{Materials and methods}

Human materials and cell lines. Bone marrow containing malignant cells was obtained from 32 patients with pediatric T-ALL and 32 age- and sex-matched healthy volunteers. Patients were admitted to The First Clinical Hospital Affiliated to Harbin Medical University (Heilongjiang, China) between June 2014 and July 2018. The inclusion criteria for recruitment were: i) Patients were diagnosed with ALL for the first time; and ii) patients had 
otherwise normal function of the major organs. The exclusion criteria were: i) Patients had received treatment for ALL in the past 3 months; ii) other clinical disorders were observed; and iii) patients failed to cooperate with the researchers. The ALL group included 19 males and 13 females (age range, 7-14 years; mean age, $10.8 \pm 1.9$ years). In the control group, there were 18 males and 14 females (age range, 7-14 years; mean age, $10.6 \pm 1.7$ years). The present study was approved by the Ethics Committee of The First Clinical Hospital Affiliated to Harbin Medical University. All participants' guardians signed informed consent.

Cells of Loucy (cat. no. CRL-2629) were obtained from the American Type Culture Collection. Cells were cultured in RPMI-1640 medium (cat. no. 30-2001; American Type Culture Collection) supplemented with $10 \%$ FBS (Sigma-Aldrich; Merck KGaA) and Penicillin-Streptomycin (100 U/ml; Sigma-Aldrich; Merck KGaA) at $37^{\circ} \mathrm{C}$ and $5 \% \mathrm{CO}_{2}$.

Reverse transcription-quantitative PCR (RT-qPCR). The GenElute $^{\mathrm{TM}}$ Total RNA Purification kit (Sigma-Aldrich; Merck KGaA) was used for RNA extraction from bone marrow samples and in vitro cultured cells, followed by preparation of cDNA samples using AMV Reverse Transcriptase (VWR International) with the following thermocycling conditions: $25^{\circ} \mathrm{C}$ for $5 \mathrm{~min}, 53^{\circ} \mathrm{C}$ for $20 \mathrm{~min}$ and $75^{\circ} \mathrm{C}$ for $10 \mathrm{~min}$. All PCR mixtures were prepared using the SuperScript III Platinum One-Step qRT-PCR kit (Thermo Fisher Scientific, Inc.). The ABI 7500 system was used to perform all PCR reactions with the following conditions: $1 \mathrm{~min}$ at $95^{\circ} \mathrm{C}$, followed by 40 cycles of $15 \mathrm{sec}$ at $95^{\circ} \mathrm{C}$ and $40 \mathrm{sec}$ at $57.5^{\circ} \mathrm{C}$. $\mathrm{C}_{\mathrm{t}}$ values were normalized using the $2^{-\Delta \Delta \mathrm{Cq}}$ method (12). Primer sequences were as follows: IncRNA AWPPH forward, 5'-GGAGCGAGATCC CTCCAAAAT-3' and reverse, 5'-GGCTGTTGTCATACT TCTCATGG-3'; ROCK2 forward, 5'-GTGTCGGCTCCT CTGATCTC-3' and reverse, 5'-GGCATGTCTGGATGACCT CT-3'; and GAPDH (reference gene) forward, 5'-CTGGAT GGTCGCTGCTTTTTA-3' and reverse, 5'-AGGGGGATG AGTCGTGATTT-3'.

Vectors and cell transfection. pcDNA3.1 vectors expressing ROCK 2 and IncRNA AWPPH were designed and prepared by Sangon Biotech Co., Ltd., along with empty vectors. Cells were cultivated overnight to reach $70-80 \%$ confluence before transfection. Lipofectamine ${ }^{\circledR} 2000$ (Invitrogen; Thermo Fisher Scientific, Inc.) was used to perform cell transfection using $15 \mathrm{nM}$ vectors. Transfection with empty vectors was used as the negative control (NC). Treatment with the Lipofectamine $^{\circledR} 2000$ reagent alone was also used as another control (C). Cells were cultivated in fresh medium for $48 \mathrm{~h}$ prior to the subsequent assays.

Cell Counting Kit-8 (CCK-8) assay. Cell proliferation was measured using the CCK- 8 assay (Sigma-Aldrich; Merck KGaA) at $24 \mathrm{~h}$ after transfection, according to the manufacturer's instructions. Briefly, $3 \times 10^{3}$ cells/well were added to a 96-well plate, followed by the addition of $10 \mu \mathrm{l}$ CCK-8 solution every $24 \mathrm{~h}$ up to $96 \mathrm{~h}$. Following incubation at $37^{\circ} \mathrm{C}$ for $4 \mathrm{~h}$, a microplate reader (Bio-Rad Laboratories, Inc.) was used to measure the absorbance at $450 \mathrm{~nm}$.
Cell apoptosis assay. Cell apoptosis was analyzed using a cell apoptosis assay $24 \mathrm{~h}$ after transfection. Cells were centrifuged at room temperature at $1,500 \mathrm{x} g$ for $10 \mathrm{~min}$ to remove the supernatant. Cells were washed with PBS and counted. Subsequently, $1 \times 10^{6}$ cells were stained with $500 \mu \mathrm{l}$ binding buffer, $5 \mu \mathrm{l}$ FITC-labeled Annexin $\mathrm{V}$ and $5 \mu \mathrm{l}$ propidium iodide solution. After incubation in the dark for $10 \mathrm{~min}$, apoptotic cells were detected using the FACSCalibur flow cytometry system (BD Biosciences). Data was analyzed using Flowing Software version 2.5 (Turku Bioscience).

Western blot analysis. Total protein was extracted from in vitro cultivated Loucy cells at $48 \mathrm{~h}$ after transfection using a Total Protein Extraction kit (cat. no. NBP2-37853; Novus Biologicals, LLC). BCA assay (Invitrogen; Thermo Fisher Scientific, Inc.) was performed to measure protein concentration. Following protein denaturation $(5 \mathrm{~min}$ in boiling water), electrophoresis was performed (30 $\mu \mathrm{g}$ per lane) using $10 \%$ SDS-PAGE, and PVDF membranes were used for gel transfer. Following incubation with 5\% skimmed milk for $2 \mathrm{~h}$ at $22^{\circ} \mathrm{C}$, membranes were incubated with ROCK2 (dilution, 1:2,000; cat. no. ab71598; Abcam) and GAPDH (dilution, 1:1,000; cat. no. ab9485; Abcam) rabbit anti-human primary antibodies for $18 \mathrm{~h}$ at $4^{\circ} \mathrm{C}$, followed by incubation with immunoglobulin G-horseradish peroxidase goat anti-rabbit secondary antibody (dilution, 1:1,000; cat. no. MBS435036; MyBioSource, Inc.) for $2 \mathrm{~h}$ at room temperature. Subsequently, membranes were incubated with ECL reagent (Sigma-Aldrich; Merck $\mathrm{KGaA}$ ) to detect signals. Data were analyzed using ImageJ v1.46 (National Institutes of Health).

Statistical analysis. GraphPad Prism 6 software (GraphPad Software, Inc.) was used for data analysis. Data are presented as the mean \pm standard deviation of three biological replicates. Differences between two groups were determined using an unpaired Student's t-test. Differences among three or more groups were analyzed using one-way ANOVA with Tukey's post hoc test. Correlations between lncRNA AWPPH and ROCK2 expression were determined using Pearson's correlation coefficient. Diagnostic values of 1ncRNA AWPPH and ROCK2 for T-ALL were determined using receiver operating characteristic (ROC) curve analysis. $\mathrm{P}<0.05$ was considered to indicate a statistically significant difference.

\section{Results}

IncRNA AWPPH and ROCK2 $\mathrm{mRNA}$ levels are upregulated in patients with pediatric T-ALL. IncRNA AWPPH and ROCK2 mRNA expression in bone marrow was detected by RT-qPCR. Compared with the control group, lncRNA AWPPH (Fig. 1A) and ROCK2 mRNA (Fig. 1B) expression was significantly upregulated in patients with T-ALL. In addition, western blotting results revealed that ROCK2 protein levels were higher in patients $(n=4)$ than in controls $(n=2)(P<0.05$; Fig. 1C). It is worth noting that due to a lack of quality protein samples, the number of assayed patients was limited.

lncRNA AWPPH and ROCK2 upregulation distinguishes patients with T-ALL from healthy controls. The diagnostic 

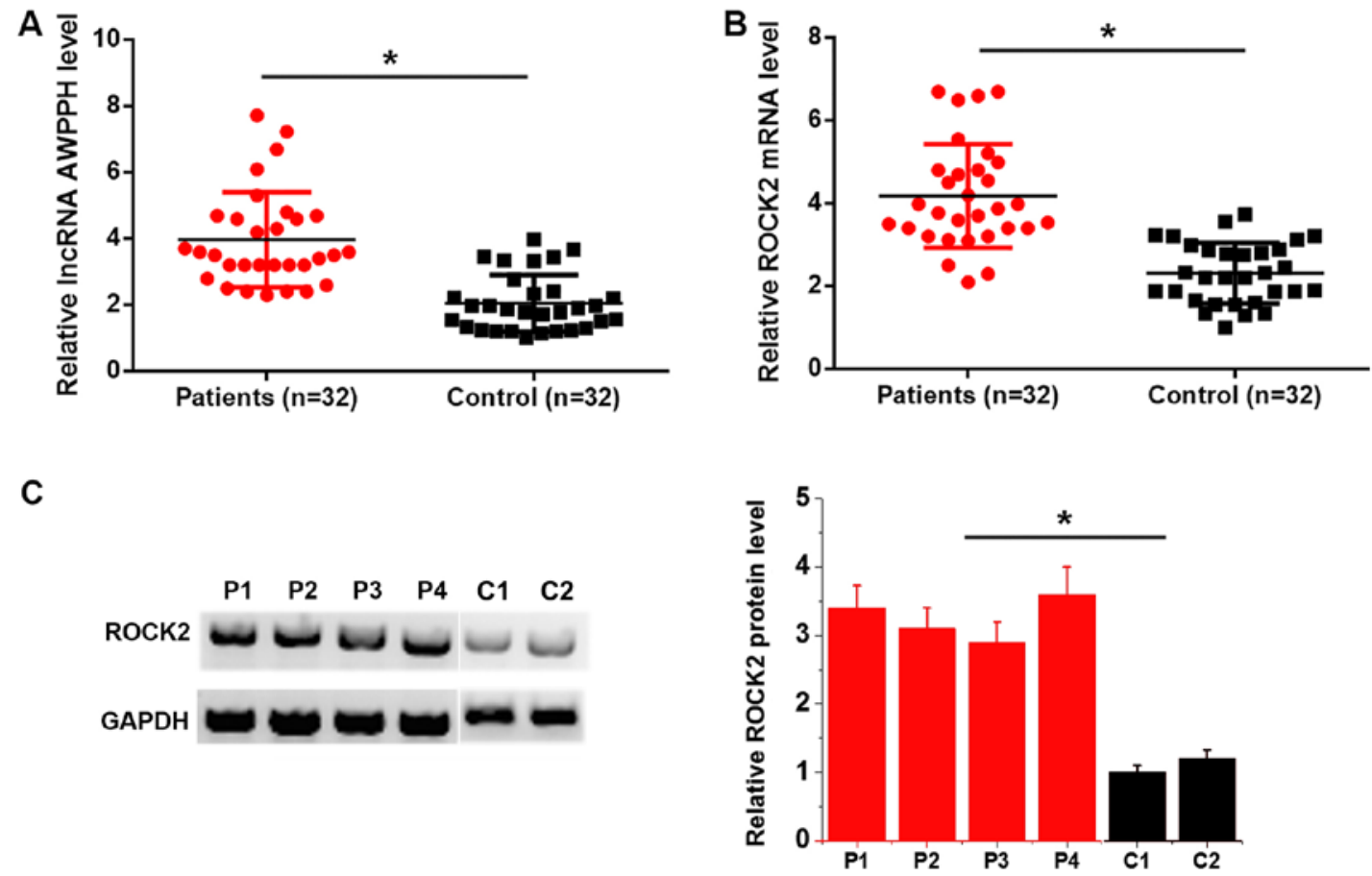

Figure 1. IncRNA AWPPH and ROCK2 mRNA levels are upregulated in patients with pediatric T-ALL. Reverse transcription-quantitative PCR results revealed that expression levels of (A) lncRNA AWPPH and (B) ROCK2 were significantly upregulated in patients with T-ALL compared with those in healthy controls. (C) Western blotting results revealed that ROCK2 protein levels were higher in $\mathrm{P}(\mathrm{n}=4)$ than in $\mathrm{C}(\mathrm{n}=2)$. Western blotting data presented were from two separate gels separated by a white line. Mean values of $\mathrm{P}$ and $\mathrm{C}$ groups were compared. "P<0.05. P, patient; $\mathrm{C}$, control; T-ALL, T-cell acute lymphoblastic leukemia; lncRNA AWPPH, long non-coding RNA associated with poor prognosis of hepatocellular carcinoma; ROCK2, Rho-associated protein kinase 2.
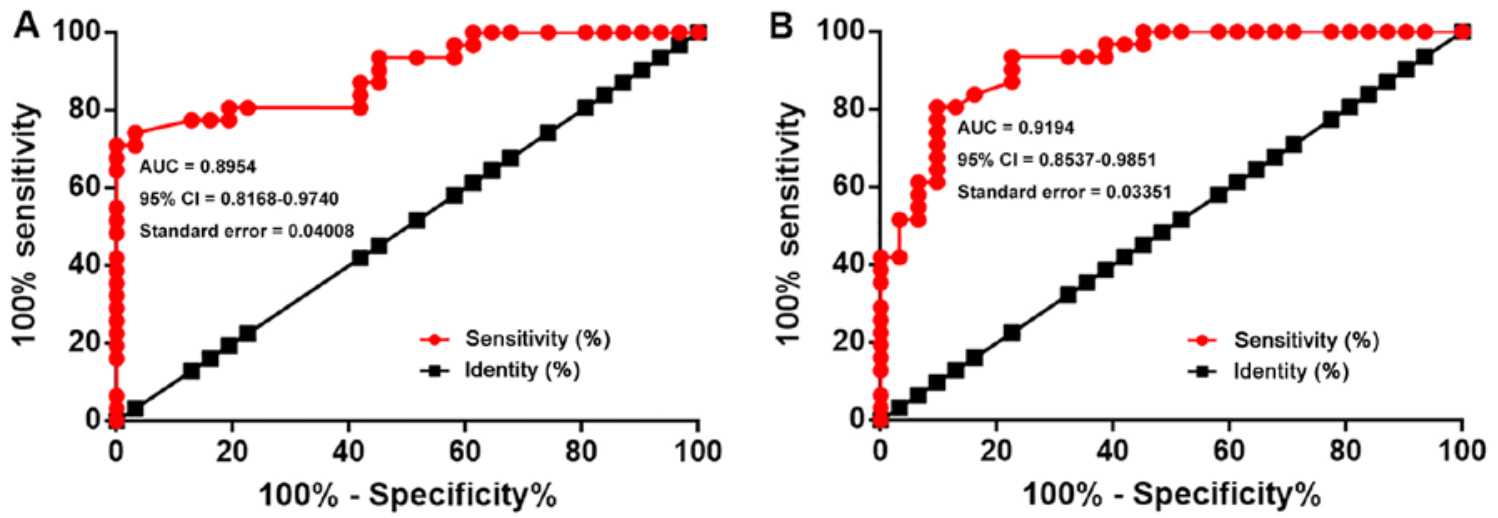

Figure 2. Upregulation of IncRNA AWPPH and ROCK2 expression distinguishes patients with T-ALL from healthy controls. Receiver operating characteristic curve analysis revealed that upregulation of (A) lncRNA AWPPH and (B) ROCK2 distinguished patients with T-ALL from healthy controls. T-ALL, T-cell acute lymphoblastic leukemia; IncRNA AWPPH, long non-coding RNA associated with poor prognosis of hepatocellular carcinoma; ROCK2, Rho-associated protein kinase 2 .

values of lncRNA AWPPH and ROCK2 for T-ALL were analyzed by ROC curve analysis. In the present analysis, true positive cases were patients with T-ALL, while true negative cases were healthy controls. For lncRNA AWPPH, the area under the curve (AUC) was 0.8954 (95\% CI, 0.8168-0.9740; standard error, 0.04008; Fig. 2A). For ROCK2 mRNA, the AUC was 0.9194 (95\% CI, 0.8537-0.9851; standard error, 0.03351; Fig. 2B).

IncRNA AWPPH and ROCK2 expression are positively correlated. The correlation between lncRNA AWPPH and ROCK2 expression was analyzed using Pearson's correlation coef- ficient. As shown in Fig. 3, the expression levels of lncRNA AWPPH and ROCK2 were positively correlated in patients with T-ALL (Fig. 3A) and in healthy controls (Fig. 3B).

IncRNA AWPPH and ROCK2 regulate each other in T-ALL cells. Expression levels of lncRNA AWPPH and ROCK2 were detected $24 \mathrm{~h}$ after transfection. As shown in Fig. 4A, overexpression of IncRNA AWPPH and ROCK 2 was achieved in the human T-ALL Loucy cell line $(\mathrm{P}<0.05$; Fig. 4A). Compared with the $\mathrm{C}$ and $\mathrm{NC}$ groups, overexpression of ROCK2 significantly upregulated lncRNA AWPPH expression ( $\mathrm{P}<0.05$; Fig. 4B). In addition, overexpression of lncRNA 

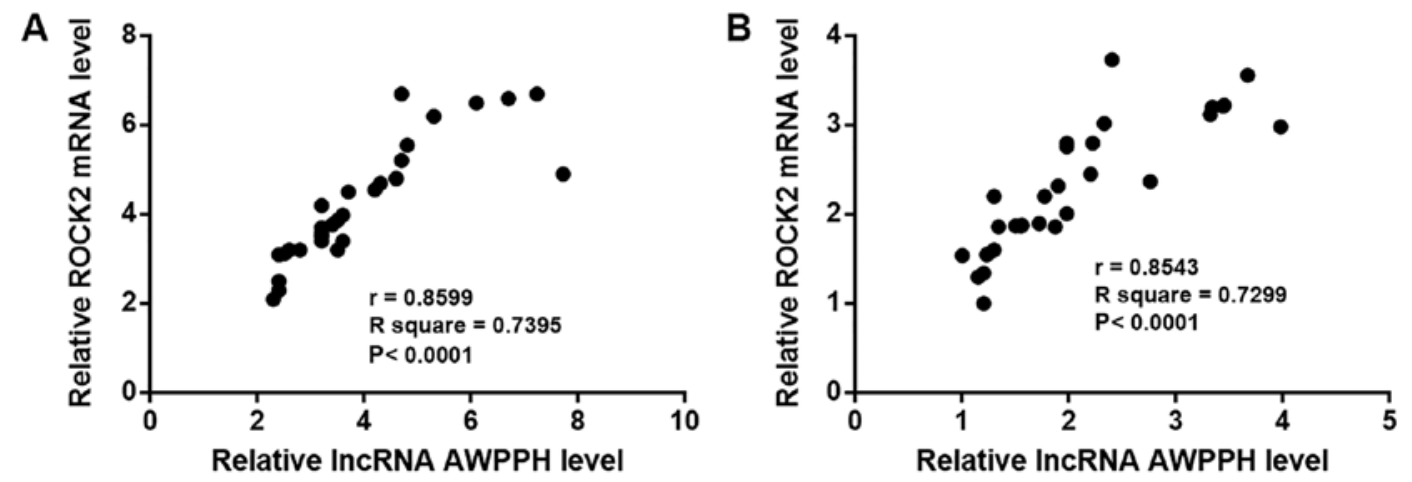

Figure 3. IncRNA AWPPH and ROCK2 expression are positively correlated. Pearson's correlation coefficient revealed that the expression levels of lncRNA AWPPH and ROCK2 were positively correlated in (A) patients with T-cell acute lymphoblastic leukemia and (B) healthy controls. lncRNA AWPPH, long non-coding RNA associated with poor prognosis of hepatocellular carcinoma; ROCK2, Rho-associated protein kinase 2.
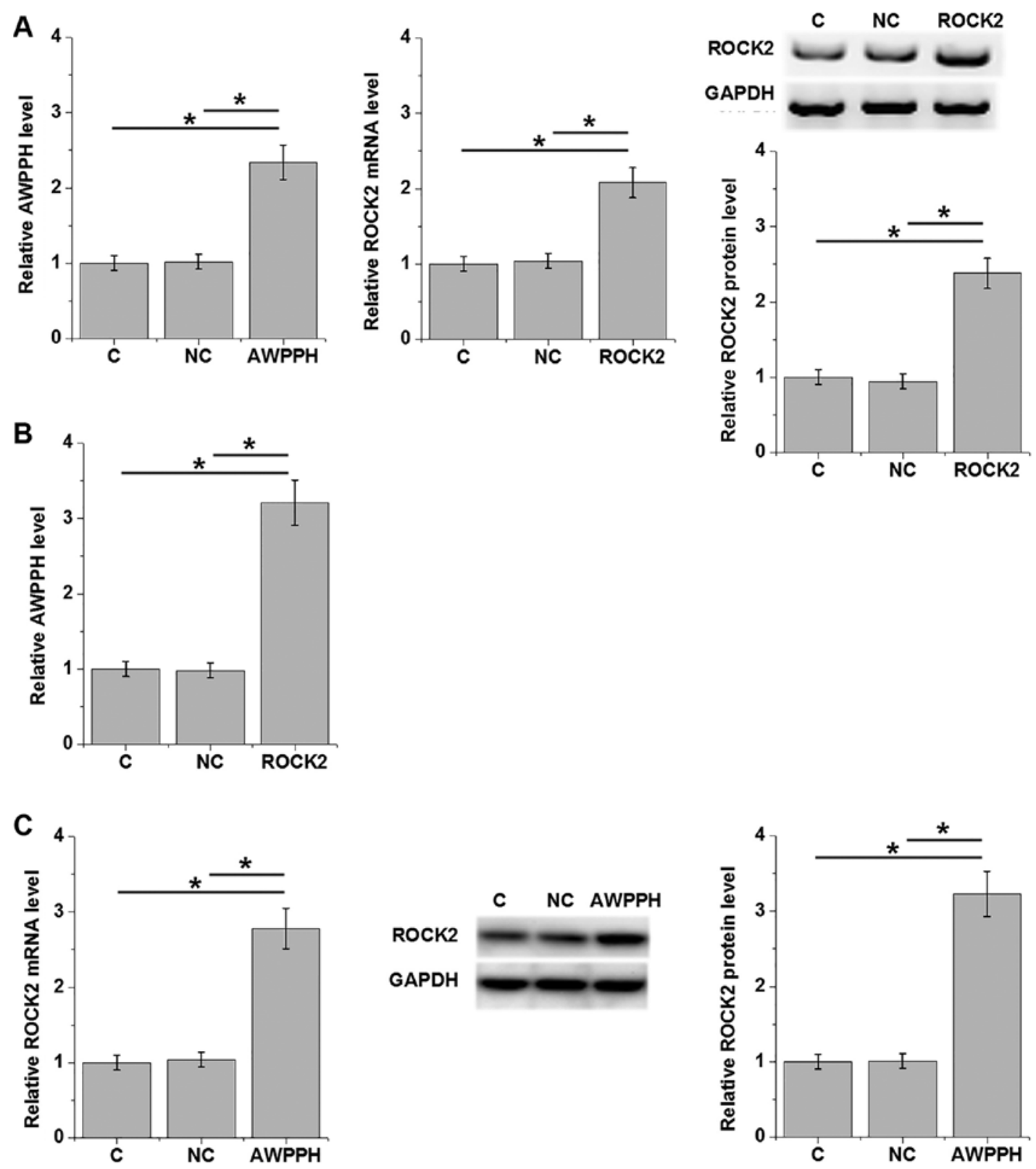

Figure 4. IncRNA AWPPH and ROCK2 regulate each other's expression in T-cell acute lymphoblastic leukemia cells. (A) Overexpression of lncRNA AWPPH and ROCK2 was achieved by transfection in Loucy cells, as displayed by reverse transcription-quantitative PCR (left and middle) and western blot analysis (right). (B) Overexpression of ROCK2 significantly upregulated lncRNA AWPPH expression. (C) Overexpression of lncRNA AWPPH upregulated ROCK2 expression at both the mRNA (left) and protein levels (middle and right). ${ }^{*} \mathrm{P}<0.05$. C, control; NC, negative control; lncRNA AWPPH, long non-coding RNA associated with poor prognosis of hepatocellular carcinoma; ROCK2, Rho-associated protein kinase 2. 

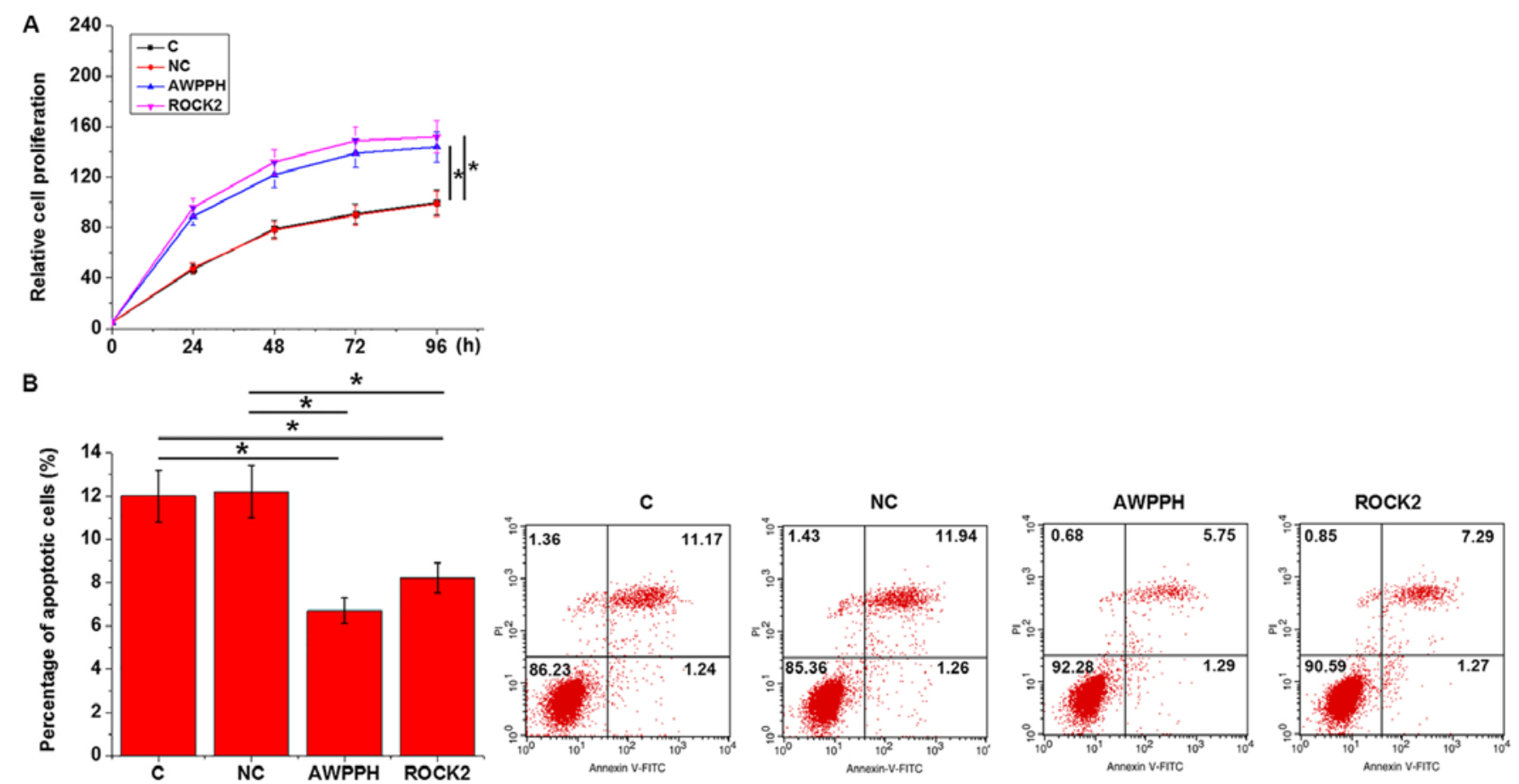

Figure 5. IncRNA AWPPH and ROCK2 overexpression regulates T-cell acute lymphoblastic leukemia cell behavior. Overexpression of either lncRNA AWPPH or ROCK2 (A) significantly promoted proliferation and (B) inhibited apoptosis of Loucy cells. "P<0.05. C, control; NC, negative control; lncRNA AWPPH, long non-coding RNA associated with poor prognosis of hepatocellular carcinoma; PI, propidium iodide; ROCK2, Rho-associated protein kinase 2.

AWPPH upregulated ROCK2 expression at both the mRNA and protein levels $(\mathrm{P}<0.05$; Fig. 4C).

IncRNA AWPPH and ROCK2 overexpression regulate T-ALL cell behaviors. Cell proliferation and apoptosis were analyzed by CCK- 8 and cell apoptosis assays, respectively, at $24 \mathrm{~h}$ after transfection. Compared with the $\mathrm{C}$ and $\mathrm{NC}$ groups, overexpression of either IncRNA AWPPH or ROCK2 significantly promoted proliferation (Fig. 5A) and inhibited apoptosis (Fig. 5B) of Loucy cells $(\mathrm{P}<0.05)$.

\section{Discussion}

lncRNA AWPPH is a recently identified oncogenic lncRNA in liver cancer and bladder cancer $(9,10)$. To the best of our knowledge, the involvement of lncRNA AWPPH in other human diseases remains unknown. The present study revealed that the expression levels of IncRNA AWPPH and ROCK2 were upregulated in pediatric T-ALL. In addition, IncRNA AWPPH and ROCK 2 overexpression upregulated each other's expression, suggesting that they may promote the development and progression of T-ALL.

Previous studies have demonstrated that the development of T-ALL is accompanied by changes in the expression patterns of a large set of lncRNAs $(13,14)$, and that the differential expression of lncRNAs defines the subtypes of this disease (13). The present study reported the upregulation of IncRNA AWPPH in pediatric T-ALL. IncRNA AWPPH has been associated with the regulation of cancer cell proliferation $(9,10)$. Consistently, the present study revealed that upregulation of IncRNA AWPPH significantly promoted the proliferation of T-ALL cells. Additionally, the present findings improved the under- standing of the function of lncRNA AWPPH, suggesting that lncRNA AWPPH may be an inhibitor of cancer cell apoptosis in T-ALL.

ROCK 2 is a type of serine/threonine kinase that is involved in the regulation of smooth muscle contraction, cytokinesis, focal adhesion and formation of actin stress fibers (15). ROCK2 is frequently upregulated in cancer development, and inhibition of ROCK2 expression can improve cancer treatment $(11,15-17)$. In the present study, ROCK2 expression was significantly upregulated in patients with T-ALL compared with in healthy controls. ROCK 2 upregulation distinguished patients with T-ALL from healthy controls.

It is well-known that ROCK2 may exert its biological functions by interacting with lncRNAs (18). Notably, in the present study lncRNA AWPPH and ROCK2 upregulated each other's expression in T-ALL cells. However, the molecular mechanism underlying the interaction between IncRNA AWPPH and ROCK 2 remains unknown. It was hypothesized that IncRNA AWPPH and ROCK2 may directly interact with each other, or that their interaction may be regulated by some non-pathological mediators, since the expression levels of IncRNA AWPPH and ROCK2 were positively correlated in both patients and healthy controls. In addition, AWPPH and ROCK2 did not affect each other's expression in silencing assays (data not shown). Therefore, AWPPH and ROCK2 may interact with each other in a unidirectional way.

However, only one cell line was used in the present study. Therefore, future studies should include multiple cell lines to further verify the conclusions made in the present study. Future studies should focus on the identification of pathological factors that mediate the interaction between lncRNA AWPPH and ROCK2. 
In conclusion, IncRNA AWPPH and ROCK2 were upregulated in pediatric T-ALL. IncRNA AWPPH and ROCK2 may upregulate each other's expression to promote the development of this disease.

\section{Acknowledgements}

Not applicable.

\section{Funding}

No funding was received.

\section{Availability of data and materials}

All data generated or analyzed during this study are included in this published article.

\section{Authors' contributions}

XL designed the experiments. XL and FS performed the experiments. HS analyzed data. XL drafted the manuscript. All authors read and approved the final manuscript.

\section{Ethics approval and consent to participate}

The present study was approved by the Ethics Committee of The First Clinical Hospital Affiliated to Harbin Medical University (Harbin, China). All participants' guardians signed informed consent.

\section{Patient consent for publication}

Not applicable.

\section{Competing interests}

The authors declare that they have no competing interests.

\section{References}

1. Ribera JM Hentrich M and Barta SK: Acute lymphoblastic leukemia//HIV-associated hematological malignancies. Springer, Cham, 145-151, 2016.

2. Chiaretti S and Foà R: T-cell acute lymphoblastic leukemia. Haematologica 94: 160-162, 2009.
3. Karrman K and Johansson B: Pediatric T-cell acute lymphoblastic leukemia. Genes Chromosomes Cancer 56: 89-116, 2017.

4. Grabher C, von Boehmer H and Look AT: Notch 1 activation in the molecular pathogenesis of T-cell acute lymphoblastic leukaemia. Nat Rev Cancer 6: 347-359, 2006.

5. Zhang J, Ding L, Holmfeldt L, Wu G, Heatley SL, Payne-Turner D, Easton J, Chen X, Wang J, Rusch M, et al: The genetic basis of early T-cell precursor acute lymphoblastic leukaemia. Nature 481: 157-163, 2012.

6. Mercer TR, Dinger ME and Mattick JS: Long non-coding RNAs: Insights into functions. Nat Rev Genet 10: 155-159, 2009.

7. Gutschner T and Diederichs S: The hallmarks of cancer: A long non-coding RNA point of view. RNA Biol 9: 703-719, 2012

8. Spizzo R, Almeida MI, Colombatti A and Calin GA: Long non-coding RNAs and cancer: A new frontier of translational research? Oncogene 31: 4577-4587, 2012.

9. Zhao X, Liu Y and Yu S: Long noncoding RNA AWPPH promotes hepatocellular carcinoma progression through YBX1 and serves as a prognostic biomarker. Biochim Biophys Acta Mol Basis Dis 1863: 1805-1816, 2017.

10. Zhu F, Zhang X, Yu Q, Han G, Diao F, Wu C and Zhang Y: LncRNA AWPPH inhibits SMAD4 via EZH2 to regulate bladder cancer progression. J Cell Biochem 119: 4496-4505, 2018.

11. Rath $\mathrm{N}$ and Olson MF: Rho-associated kinases in tumorigenesis: Re-considering ROCK inhibition for cancer therapy. EMBO Rep 13: 900-908, 2012.

12. Livak KJ and Schmittgen TD: Analysis of relative gene expression data using real-time quantitative PCR and the 2(-Delta Delta C(T)) method. Methods 25: 402-408, 2011.

13. Wallaert A, Durinck K, Van Loocke W, Van de Walle I, Matthijssens F, Volders PJ, Avila Cobos F, Rombaut D, Rondou P, Mestdagh $\mathrm{P}$, et al: Long noncoding RNA signatures define oncogenic subtypes in T-cell acute lymphoblastic leukemia. Leukemia 30: 1927-1930, 2016.

14. Ngoc PC, Tan SH, Tan TK, Chan MM, Li Z, Yeoh AEJ, Tenen DG and Sanda T: Identification of novel lncRNAs regulated by the TAL1 complex in T-cell acute lymphoblastic leukemia. Leukemia 32: 2138-2151, 2018

15. Nakagawa O, Fujisawa K, Ishizaki T, Saito Y, Nakao K and Narumiya S: ROCK-I and ROCK-II, two isoforms of Rho-associated coiled-coil forming protein serine/threonine kinase in mice. FEBS Lett 392: 189-193, 1996.

16. Vigil D, Kim TY, Plachco A, Garton AJ, Castaldo L, Pachter JA, Dong H, Chen X, Tokar B, Campbell SL and Der CJ: ROCK1 and ROCK2 are required for non-small cell lung cancer anchorage-independent growth and invasion. Cancer 72: 5338-5347, 2012.

17. Wang L, Hou G, Xue L, Li J, Wei P and Xu P: Autocrine motility factor receptor signaling pathway promotes cell invasion via activation of ROCK-2 in esophageal squamous cell cancer cells. Cancer Invest 28: 993-1003, 2010.

18. Shi S, Peng Q, Shao X, Xie J, Lin S, Zhang T, Li Q, Li X and Lin Y: Self-assembled tetrahedral DNA nanostructures promote adipose-derived stem cell migration via lncRNA XLOC 010623 and RHOA/ROCK2 signal pathway. ACS Appl Mater Interfaces 8: 19353-19363, 2016.

This work is licensed under a Creative Commons Attribution-NonCommercial-NoDerivatives 4.0 International (CC BY-NC-ND 4.0) License. 